\title{
IMPROVEMENTS IN THE PREPARATION OF $d$-GALACTURONIC ACID
}

\author{
By William Ward Pigman
}

\begin{abstract}
Many plant materials, particularly the pectins, consist to a considerable extent of polymers of $d$-galacturonic acid. Of the methods available for the preparation of $d$-galacturonic acid, enzymatic methods are considered preferable, since the acid is rapidly decomposed by hot mineral acids. The use of enzymes for this purpose has been previously described, but the methods either result in poor yields or employ materials or enzymes not conveniently available. The present paper describes an improved method which results in yields of $d$-galacturonic acid of more than 67 percent of the theoretical values and which makes use of commercially available materials.
\end{abstract}

The uronic acids are important and widely distributed constituents of natural products. Pectin, an important carbohydrate, has been shown by Ehrlich and his collaborators ${ }^{1}$ to be primarily a polymer of galacturonic acid. Another well-known uronic acid is glucuronic acid, which functions in animals as a detoxifying agent and is usually made by feeding animals substances such as benzoic acid. The glucuronide formed is recovered from the urine of the animal and converted to the acid. These acids have the formula $\mathrm{CHO}-(\mathrm{CHOH})_{4}-\mathrm{COOH}$ (written as the free aldehyde form). They have the properties of sugars and acids and are capable of forming a great number of derivatives and of undergoing many isomeric transformations. The older methods of preparation of the uronic acids have not been very satisfactory, and as a result their price has been very high.

Since the uronic acids are relatively easily decomposed by acids, ${ }^{2}$ biological methods for their preparation would seem to be preferable to methods using acid hydrolysis. ${ }^{3}$ Ehrlich $^{4}$ has reported an enzymatic method which gives high yields, but which requires materials not easily obtained in this country. Mottern and Cole, ${ }^{5}$ however, have reported a method which uses commercially available citrus pectic acid (citrus polygalacturonide) and pectinase and thus have provided a very convenient method for the preparation of galacturonic acid. The method consists in its essentials in hydrolyzing a pectin derivative with a commercial pectinase preparation and then extracting the $d$-galacturonic acid with ethyl alcohol. The maximum yield reported for the Mottern and Cole method has been 37 percent of the

1 F. Ehrlich, Z. angew. Chem. 40,1305 (1927).

R. L. Whistler, A. Martin, and M. Harris, J. Research NBS 24, 13 (1940) RP1268.

F. Ehrlich and F. Schubert, Ber. deut. chem. Ges. 62, 1974 (1929).

S. Morell, L. Bauer, and K. P. Link, J. Biol. Chem. 105, 15 (1934).

' F. Ehrlich, A bderhalden's Handbuch der biologischen Arbeitsmethoden, Abt. 1, Teil 11, 1617 (1936); F. Ehrlich, Enzymologis 3, 185 (1937).

H. H. Mottern and H. L. Cole, J. Am. Chem. Soc. 61, 2701 (1939). 
theoretical, ${ }^{6}$ while Ehrlich (see footnote 4) has obtained yields of 85 percent.

It has now been found that by the use of methyl alcohol as a solvent and by a few minor changes in the Mottern and Cole procedure, it is possible to increase the average yield to more than 70 percent of the weight of the citrus polygalacturonide used as the starting material. Assuming the galacturonic content of the citrus polygalacturonide to be 95 percent (see footnote 7 ), this corresponds to a theoretical yield of 67 percent. Since the materials used are all commercial products of comparatively low cost, and since the procedure is simple, $d$-galacturonic acid can be produced at a cost not greatly exceeding some of the fairly common sugars, such as $d$-galactose.

The methyl alcohol has the advantage that it dissolves the galacturonic acid much more readily than ethyl alcohol and also that the extent of conversion to more soluble isomers is lessened. In the original method, considerable galacturonic acid was left in the insoluble residue. This was proved, since such residues were found to yield considerable quantities of galacturonic acid when they were extracted with methyl alcohol. This probably also explains the increase in yield reported by Manville, Reithel, and Yamada (see footnote 6), who gave the residue an acid treatment and extraction. The acid treatment has now been found to be unnecessary and probably detrimental, since the mother liquors are decomposed by the acid.

Procedure.-Two solutions were prepared as follows and combined after the hydrolytic period. To $2,600 \mathrm{ml}$ of water stirred well at $40^{\circ} \mathrm{C}$, there was added $260 \mathrm{~g}$ of citrus polygalacturonide ${ }^{7}$ and then $385 \mathrm{ml}$ of $3 \mathrm{~N}$ sodium hydroxide. To this viscous solution, which has a $\mathrm{pH}$ of about 3.7 at $37^{\circ} \mathrm{C}$, there was added $20 \mathrm{~g}$ of pectinase, ${ }^{8}$ and the solution was kept at $38^{\circ} \mathrm{C}$ for 10 to 14 days. Mold growth was prevented by covering the surface of the solution with a thin layer of toluene.

After the period of hydrolysis, the two solutions were combined and an amount of sulfuric acid equivalent to the sodium hydroxide originally used was added. The solution was filtered with the help of diatomaceous earth and the residue washed with $700 \mathrm{ml}$ of water. The filtrate was treated with $170 \mathrm{~g}$ of activated charcoal (Norite) and filtered after 24 hours. The thick sirup obtained by evaporating the filtrate weighed $737 \mathrm{~g}$ and was treated with 2 liters of boiling methyl alcohol. The solution was heated to the boiling point and then separated from the crystalline salts (principally sodium sulfate) by filtration. The salts were then given a second extraction by boiling them for 5 minutes with a 1-liter portion of methyl alcohol. When the extractions were carried out carefully, two were found to be sufficient.

The combined extracts were evaporated under reduced pressure to a volume of about $900 \mathrm{ml}$, and the addition of a small amount of ethyl alcohol sufficed to saturate the solution. The solution, after seeding, was kept for 24 to 48 hours in a refrigerator at about $5^{\circ} \mathrm{C}$, and during this time it was stirred frequently. The crystals, after

\footnotetext{
${ }^{6}$ I. Manville, F. Reithel, and P. Yamada, J. Am. Chem. Soc. 61, 2973 (1939).

7 K. P. Link and R. Neddon, J. Biol. Chem. 94, 307 (1931-32). The product was supplied by the California Fruit Growers Exchange, Ontario, Calif., under the name of citrus pectic acid.

8 The material used was Röhm and Haas Pectinol 46AP, standardized with diatomaceous earth (100D) It is not known with certainty, but it is believed that this enzyme material is the same as that reported by $Z$. I. Kertesz, J. Am. Chem. Soc. 61, 2544 (1939), as being produced by the precipitation with ethyl alcohol of a water extract from Aspergillus sp. grown on a special medium.
} 
separation by filtration, washing with methyl alcohol containing 10 to 20 percent of water, and thorough drying at room temperature, weighed $255 \mathrm{~g}$. The mother liquors were evaporated to a thin sirup, methyl alcohol was added until amorphous material began to precipitate and the solution was allowed to crystallize in the refrigerator for several days. The crystals, washed and dried as before, weighed $71 \mathrm{~g}$. The mother liquors were then worked up by repeating the following procedure until practically all of the methyl alcohol-soluble material had been obtained in crystalline condition. The mother liquors were evaporated in vacuo to a thick sirup ${ }^{9}$ which was extracted by boiling several times with methyl alcohol. The solution was separated from the insoluble material ${ }^{10}$ by decantation and concentrated to a thin sirup, which was allowed to crystallize for several days at a low temperature. Sometimes the addition of methyl or absolute ethyl alcohol is advantageous. The crystals were washed with 80- to 90-percent methyl alcohol. From the mother liquors, $59 \mathrm{~g}$ more of fairly white material was obtained.

The first crops weighed $254 \mathrm{~g}$, were white in color, and had a melting point of $109^{\circ}$ to $112^{\circ} \mathrm{C}$. The equilibrium rotation was $[\alpha]_{D}^{20}=+51.5$ $(c, 4)$. The almost colorless materials of slightly lower purity weighed $130 \mathrm{~g}$, melted at $105^{\circ}$ to $107^{\circ} \mathrm{C}$, and had an equilibrium rotation of $[\alpha]_{D}^{20}=+51.5$ (c, 5.2). The pure galacturonic acid monohydrate, called the alpha isomer by Ehrlich and Schubert (see footnote 3), melts at $156^{\circ}$ to $159^{\circ} \mathrm{C}$ after sintering at $110^{\circ} \mathrm{C}$, and its equilibrium rotation (see footnote 3) is $[\alpha]_{D}^{20}=+50.9$. The total yield is then $385 \mathrm{~g}$, or 74 percent, of the weight $(520 \mathrm{~g})$ of the starting material.

Washington, July 16, 1940.

\footnotetext{
The temperature of the outside bath during the final stages of the evaporation should be kept as low as possible.

${ }_{10}$ This amorphous organic material is quite acid and presumably is an isomer of galacturonic acid or is a condensation product of this acid possibly analogous in structure or in origin to the Schardinger dextrins, which are obtained in a similar way. Additional quantities of this material have also been obtained by extracting the sodium sulfate residue with boiling 85-percent methyl alcohol.
} 